Alysa Routtenberg

\title{
A Century of British Columbia Landscapes Through the Lens of the Leonard Frank Photography Studio
}


The Jewish Museum and Archives of British Columbia's (JMABC) most significant photograph collection, the Leonard Frank Photography Studio fonds, encompasses tens of thousands of photos that have been featured in publications, exhibits, and research projects for decades. Despite this frequent exposure, these photos never cease to take my breath away.

Photographers Leonard Frank and Otto Landauer captured almost a century of British Columbia's history working as the collective Leonard Frank Photography Studio. The men, each the subject of an individual book published by the JMABC's Cyril E. Leonoff in 1990 and 1997 respectively, have been studied in depth and never seem far from mind in the archives.

Leonard Frank, a German-born immigrant, arrived in British Columbia in I894 by way of San Francisco almost exactly a century before I was born. The province that he saw was somehow both exactly the same and yet so far removed, it would be unrecognizable to him today. Frank travelled around the province, working on a series of government contracts to photograph engineering projects and having adventures of his own.

The resulting photographs are beyond description, stunning vistas of lakes, mountains, and forests that are each more unique and breathtaking than the last.

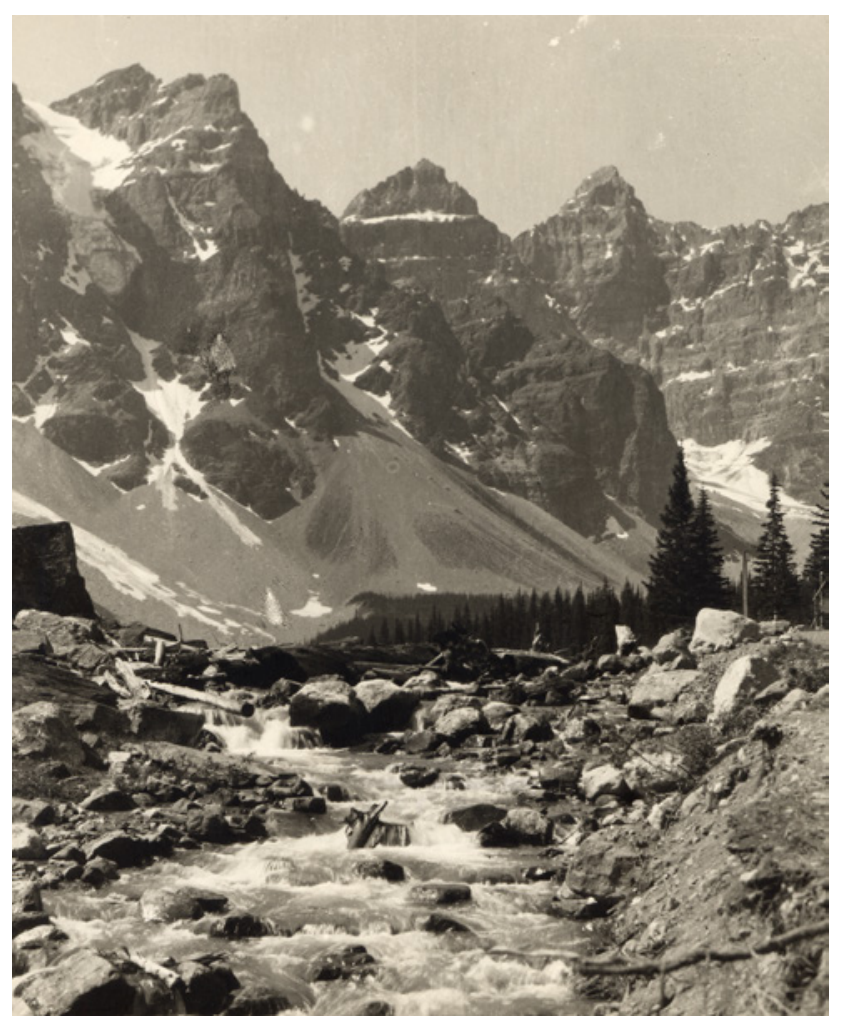

LF.01189, High mountain peaks, British Columbia, 1950. 


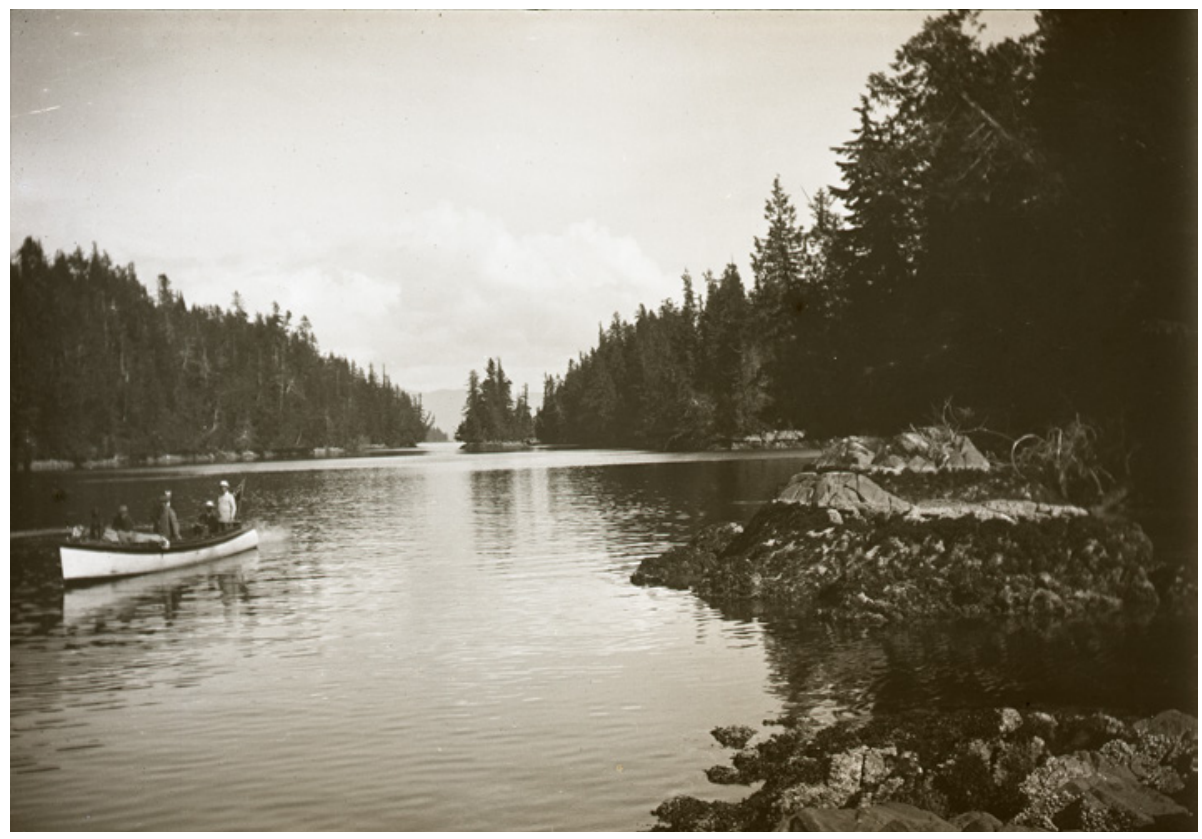

LF.00189, Pacific Great Eastern Railway Bridge under construction over Fraser River, Lillooet, British Columbia, 1920.

Otto Landauer followed in the footsteps of Leonard Frank. After buying the photography studio in 1947 , he continued Frank's portfolio and expanded it to include more urban construction projects, especially in the Lower Mainland. Though individual in their exact subject matter, I have often seen researchers calmly slip from one photographer to the next, seeing a natural evolution which does not raise questions until the dates are noticed, leaving the researcher to wonder if one person could have worked from 1895 through to 1980. Both men, for example, completed projects at the University of British Columbia during construction, capturing different eras within one institution.

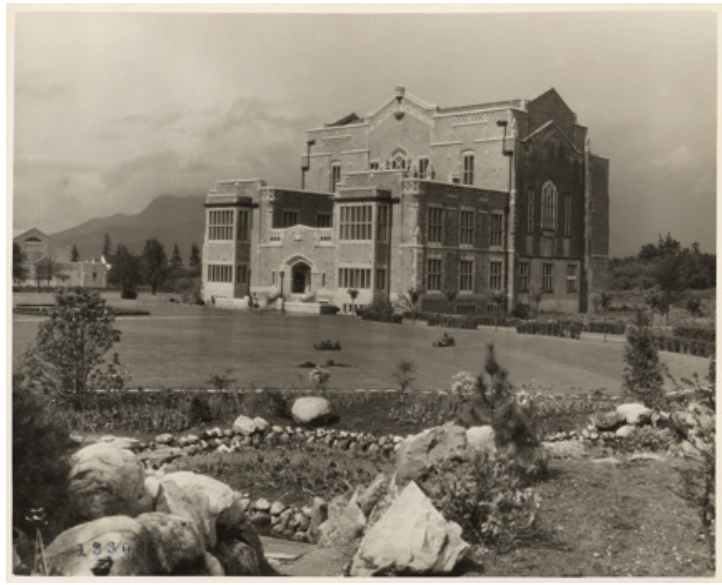


The collection features occasional glimpses into the men's personal lives, with family and holiday photographs appearing sporadically. More than these purposeful breaks, so much about their personalities can be gleaned from the more standard or representative photographs, with each using human subjects sparingly, and their obvious investment in nature and urban development.

Interacting with the collection, I am struck again and again by a few experiences that can best be described on a spectrum; from landscapes that have not changed a bit, to recognizable but contextually different landmarks, to views and perspectives that are lost to us today. The steps along this spectrum intriguingly have almost nothing to do with chronology, seeming to best relate to proximity to cities, or the wilderness. It is remarkable to me that such sparsely populated photographs can evoke such strong feelings, but time and again the trees, lakes, and mountains speak for themselves. The photographs depicting the construction of buildings, bridges, and mines similarly inspire a nostalgia for a time of building and growth that I have never personally known.

Frank's photograph of the Lions (or Ch'ich'iyúy Elxwíkn [Twin Sisters] in original Squamish) is likely his best known and most frequently seen work.

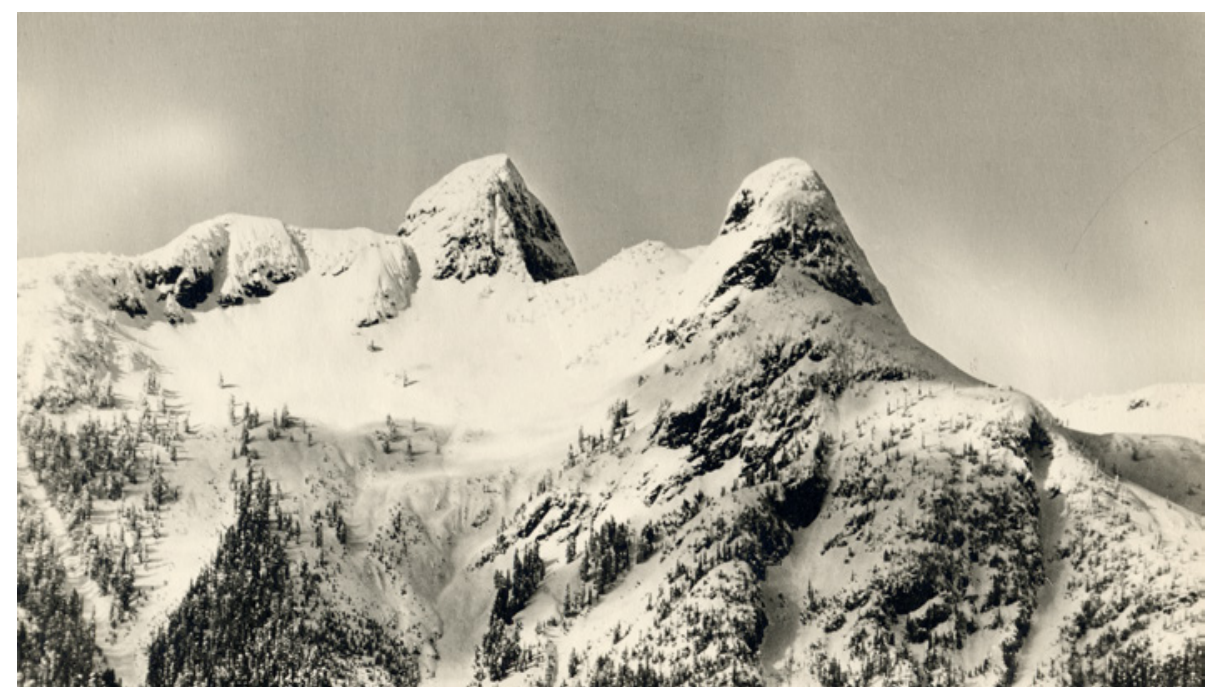

LF.01303, The Lions, scenic collection, 1920.

The peaks, still visible from many spots around Vancouver look relatively unchanged today, though nothing around them is the same as a century ago. Vancouver was just a seedling when the photo was taken, in 1919, with a population of less than II7,000. The view has not changed to the naked eye but the landscape that it is a part of has changed forever. This is true of many other photographs in the collection, the lakes 
and ravines and mountains pictured can still be hiked to, by a dedicated person, and found relatively unchanged today. Frank's skill as an outdoorsman is something that often strikes me looking at his photographs, especially from places I know today. To traipse up a mountain that presumably lacks the City of Vancouver signage and guardrails it now has with a camera and supplies in tow, tells me something of whom Frank was a person. It is hard to put a finger on the feeling exactly, but his dedication to both the outdoors and capturing it on film is palpable.

On this spectrum of almost Ioo years of photos, there is a middle ground of images that are interesting in their own right: places that I can recognize today despite massive changes they have undergone. Otto Landauer's photographs of the city, captured from 1940 to 1980 , are where I face cityscapes that are so familiar and yet completely separate from the experience of living in Vancouver today. Seeing these familiar landmarks through another person's eyes never fails to take me out of myself for a minute, a welcome intrusion in one's life.

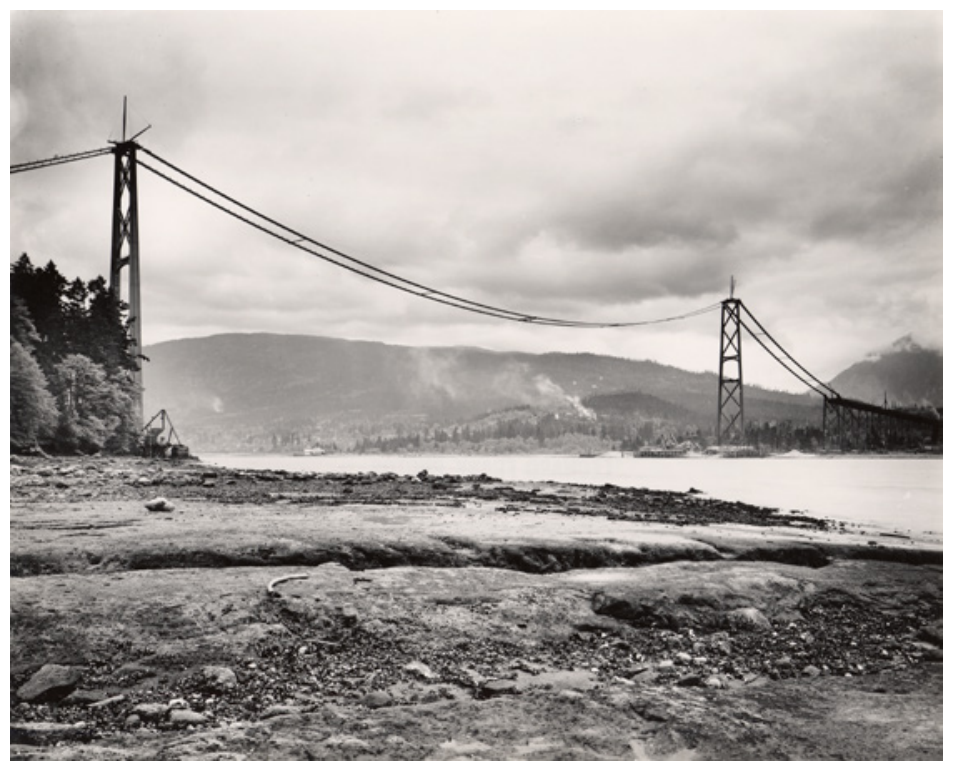

LF.02722, Lion's Gate Bridge mid-construction, undated.

Other photographs in the collection, especially a series of logging activities, and the building of mills, mines, and dams feel almost in motion, capturing teams of men changing the landscape right there in Frank's lens. The logging of ancient cedars is almost hard to look directly at today, in a world of clear-cut forests and pipelines, but the teams of men grin and show off their incredible feats of strength. 


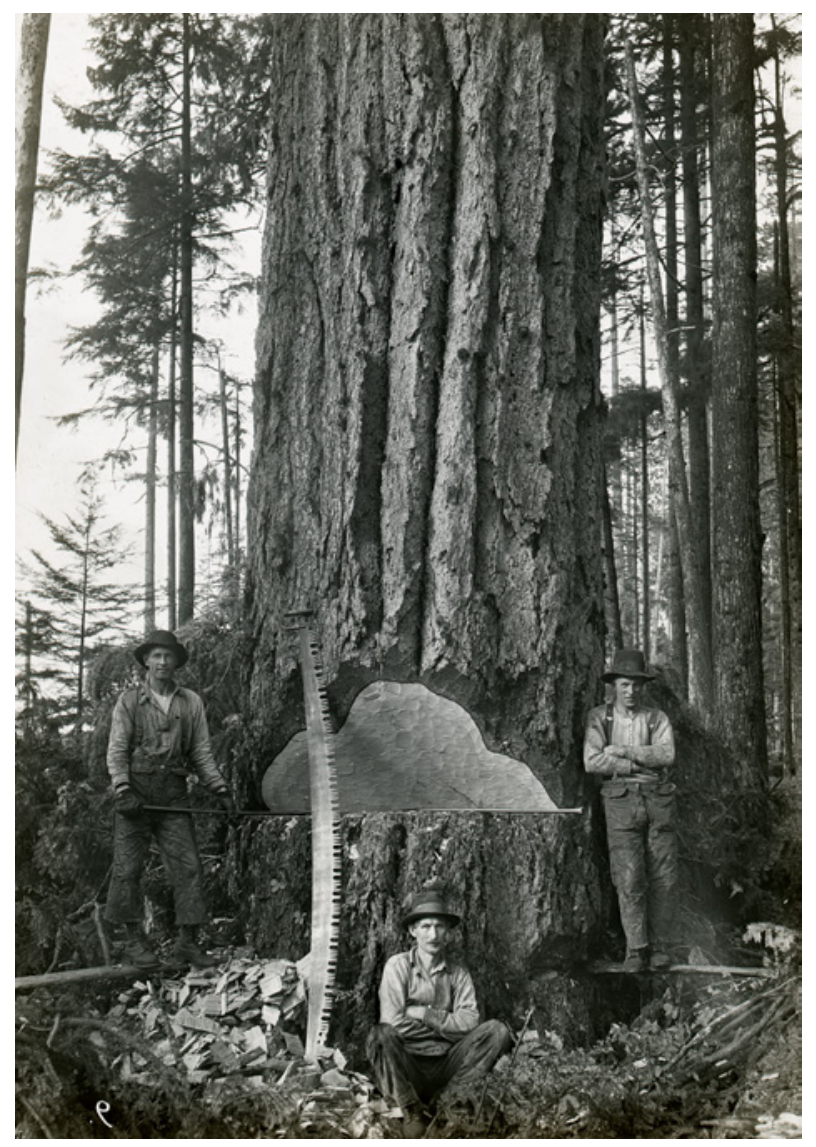

LF.38826, Loggers cutting down a cedar tree, undated.

I cannot speculate about their mindset and awareness more than a hundred years later, it is beyond the role of archivists and indeed, feels impossible to even the most imaginative. None of this changes the effect they had on our province's future, though, remorseful or gleeful though the workers may have been, these trees were logged and turned into the architecture of the city I live in today. In recent viewings, I have come to accept these photographs simply for what they are: a glimpse of past lives. I thank the workers for their endless hours toiling in the wilderness, the trees for building the society I know today, and Leonard Frank for being there to capture it all. Learning again and again to accept the photographs for what they are without asking more of them is a constant process, and works well today, but in five, ten, or twenty-five years I wonder how perspectives might have once again changed.

Though Otto Landauer died in 1980, this collection has continued to live many lives since. The majority of the collection resides with the JMABC, with a small collection in Vancouver Public Library's Special Collections, and individual photographs sprinkled over community archives and personal collections through the province and the 
world. While processed and in good condition, the massive collection of negatives and prints is always a candidate for future projects. Further cataloguing and digitization are long-term goals; with approximately 5000 images digitized, this is just the tip of the iceberg. Additionally, in the past year conversations about indigenization and connections between First Nations and Jewish communities have inspired a potential future project: to add back to the catalogue the First Nations place names of Frank and Landauer's locations. Much like my archivists' perspective on the collection today, it is impossible to say how best practices around these photographs might change, but we know they have many stories left to tell. 